\title{
"MANCHA-CAFÉ" EM SOJA: SELEÇÃO PARA RESISTÊNCIA E INTERAÇÃO ENTRE GENÓTIPOS E ÉPOCAS DE INOCULAÇÃO $\left({ }^{1}\right)$
}

\author{
ANDRÉ LUIZ LOURENÇÃO $\left({ }^{2,5}\right)$, MANOEL ALBINO COELHO DE MIRANDA $\left({ }^{3}\right)$ \\ e ÁLVARO SANTOS COSTA $\left({ }^{4}\right)$
}

\begin{abstract}
RESUMO
Em condições de campo, realizaram-se seleções em linhagens de soja contra manchamento de sementes causado pelo vírus do mosaico comum da soja (VMCS). Conhecido como "mancha-café", o sintoma caracteriza-se pelo derramamento dos pigmentos do hilo da semente. Produzidas no Centro Experimental de Campinas, pertencente ao IAC, as sementes de 131 linhagens da geração $F_{5}$ do cruzamento entre IAC78-2318 e 'Santa Rosa' (ambos suscetiveis ao VMCS) foram avaliadas, em 1987, quanto ao grau de manchamento, de acordo com uma escala de notas de 1 (sementes sem manchas) a 5 (sementes com tegumento quase totalmente manchado). Quatro linhagens obtiveram nota 1, enquanto a maioria recebeu nota 3. Essa distribuição de notas pode indicar que a herança da resistência ao manchamento da semente é de origem poligênica. Para verificar a repetibilidade do manchamento, em 1988, nas mesmas condições, procedeu-se ao ensaio com dezessete linhagens avaliadas no ano anterior mais o cultivar Santa Rosa, representando as cinco notas. Houve similaridade entre as notas nos dois anos, sendo o valor do coeficiente de correlação (r) igual a 0,96 , altamente significativo. Para estudar o efeito da inoculação do vírus em três estádios fenológicos em linhagens e cultivares, realizou-se, em 1992, um experimento em casa de vegetação. Efetuaram-se inoculações mecânicas em cinco linhagens (uma de cada nota) mais os genótipos Santa Rosa, IAC-Santa Rosa DF e IAC-Santa Rosa PC, nos estádios $V_{2}-V_{3}, V_{5}-V_{6}$ e $R_{1}$, segundo a escala de Fehr. Avaliou-se a incidência de "mancha-café", a massa e o número de sementes por três plantas, a presença de haste-verde (senescência anormal) e a massa de cem sementes. A linhagem IAC87-5934, com nota 1 nas avaliaçōes de 1987 e 1988, mostrou a menor incidência de "mancha-café" em todas as épocas de inoculação, sendo a única que não apresentou plântulas com sintomas de mosaico, oriundas de sementes de plantas que haviam sido infectadas no estádio vegetativo. Esses resultados fortalecem a diretriz utilizada no programa de melhoramento da Seção de Leguminosas do IAC: a de eliminar plantas e/ou linhagens com incidencia de "mancha-café".
\end{abstract}

Termos de indexação: Glycine max, vírus do mosaico comum da soja (VMCS), resistência.

(1) Recebido para publicação em 7 de junho de 1995 e aceito em 3 de janeiro de 1996.

(2) Seção de Entomologia Fitotécnica, Instituto Agronômico (IAC), Caixa Postal 28, 13001-970 Campinas (SP).

$\left({ }^{3}\right)$ Seção de Leguminosas, IAC.

(4) Seção de Virologia Fitotécnica, IAC.

${ }^{5}$ ) Com bolsa de pesquisa do CNPq. 


\title{
ABSTRACT \\ SEEDCOAT MOTTLING IN SOYBEANS: SELECTION FOR RESISTANCE AND INTERACTION BETWEEN GENOTYPES AND INOCULATION DATE
}

\begin{abstract}
The soybean mosaic virus (SMV) is widespread in all soybean production areas. The mottled brown seed is the most characteristic symptom under our conditions, so in Brazil the disease was called "mancha-café" (coffee-spot). The mottling was the main limiting factor to the seed production in the certification system. The present paper had two objetives: screenning lines with different levels of mottled seeds, and to verify the interaction between selected genotypes and inoculation dates. During 1987, $131 \mathrm{~F}_{4: 5}$ experimental lines from the cross IAC78-2318 x Santa Rosa, both susceptible to SMV, were evaluated under field conditions in Campinas (SP), Brazil. In the next year, seventeen selected lines plus the cultivar Santa Rosa, representing the five levels of mottling were planted again under field conditions in randomized complete-block design, with six replications. The results showed that the screenning realized in the field was efficient to identify the lines with different levels of mottled seeds. It was also observed that this characteristic was not much influenced by environmental effects as indicated by the positive and high correlation between diseases notes of both years, as well as the low value of the coefficient of variation. An additional study was carried out under greenhouse conditions to evaluate genotypes in distinct growth stages when mechanically inoculated with the virus. It consisted of a factorial experiment, involving a non-inoculated control, three inoculation times, and five lines representing notes from 1 to 5 , plus the cultivars Santa Rosa, IAC-Santa Rosa PC and IAC-Santa Rosa DF. The genotypes were sowed in plastic bags and at the maturity, the following evaluations were made: the mottled seed rate, seed production ( $/ 3$ plants), mass ( $g$ ) of 100 seeds and the rate of green stem. The line IAC87-5934, which scored one under field conditions, also showed the lowest mottled seed rate in all inoculation growth stages. It was also the only one that did not transmit the virus by the seeds in this experiment.
\end{abstract}

Index terms: Glycine max, soybean mosaic virus (SMV), plant resistance.

\section{INTRODUÇÃO}

Pertencente aos potyvírus, considerado o maior grupo de vírus fitopatogênicos, o vírus do mosaico comum (VMCS) está presente em todas as regiões produtoras de soja do mundo, atingindo 'status' de importante doença em certas áreas (Sinclair, 1982).

O maior prejuízo causado pelo VMCS, em São Paulo, está relacionado ao aparecimento da "mancha-café", caracterizada pelo derramamento dos pigmentos do hilo sobre o tegumento da semente; manifesta-se praticamente em $100 \%$ de sementes produzidas por variedades suscetíveis, quando as plantas são infectadas antes do florescimento (Costa Lima Neto \& Costa, 1976).
O VMCS é transmitido pela semente e por diversas espécies de afídeos (Costa, 1977). Segundo esse autor, sua transmissão pela semente foi maior no passado; atualmente, tem-se revelado baixa em testes, utilizando-se sementes de plantas afetadas de cultivares em uso. A transmissão do vírus dentro do campo de soja é realizada por várias espécies de afídeos que, normalmente, não colonizam as plantas; adquirem-no ao se alimentarem em plantas doentes, transmitindo-o às sadias (Costa, 1977). No Brasil, já se verificou transmissão do VMCS em soja por sete espécies de sete gêneros diferentes de afídeos (Costa et al., 1970; Costa Lima Neto \& Costa, 1975; Costa, 1977). Sinclair (1982) relacionou 31 espécies de afídeos como vetores do VMCS. 
A infecção de plantas jovens provoca o nanismo e a redução acentuada do número de vagens, além de sintomas típicos nas folhas, como rugosidade do limbo e manchas em mosaico de áreas verde-escuras e verde-claras. Quando a infecção ocorre em plantas adultas, os sintomas mais característicos são maturação retardada e formação de sementes com "mancha-café" (Yorinori, 1982).

Para controle dessa moléstia, Sinclair (1982) recomenda o uso de sementes oriundas de campos sem VMCS, a eliminação de plantas doentes em campos de produção, o uso de cultivares e de variedades resistentes, respectivamente, à infecção e à transmissão pela semente.

As primeiras evidências da existência de diferentes estirpes do VMCS foram relatadas por Ross (1969). Cho \& Goodman (1979), trabalhando com genótipos infectados de diversas origens, descobriram que as diferentes estirpes poderiam ser reunidas em sete grupos, designados G1-G7, de cultivares diferenciais. Posteriormente, esse sistema se expandiu com a inclusão do grupo C14 (Cho \& Goodman, 1982; Lim, 1985). Segundo Zhang, citado por Junyi et al. (1989), ainda não se obteve um sistema único para a diferenciação dos diversos grupos de estirpes do VMCS.

O conhecimento da herança da resistência e da genética da interação patógeno-hospedeiro é essencial para programas de melhoramento que visem ao controle do VMCS. O primeiro estudo da herança da resistência ao VMCS foi realizado por Kiihl \& Hartwig (1979); os autores verificaram que tanto a PI 96.983 como o cultivar Ogden mostravam um gene de resistência, dominante em relação à suscetibilidade. O gene do 'Ogden' diferia do da PI 96.983 por produzir reação necrótica sob a ação do "strain" SMV-1-B, que, por sua vez, pertence ao grupo G3 (Buss et al., 1989). O gene da PI 96.983 é alélico e dominante em relação ao do 'Ogden'. Os alelos encontrados na PI 96.983, no 'Ogden' e nos cultivares suscetíveis receberam as designações Rsv, rsv ${ }^{\mathrm{t}}$ e rsv respectivamente. Buzzell $\& \mathrm{Tu}$ (1984) constataram que, em uma linha derivada de cruzamento com o cultivar Raiden (PI 360.844), também havia um gene de resistência Rsv2 às estirpes dos grupos G1-G7. Os estudos das populações segregantes mostraram que não havia alelismo entre os dois genes, Rsv e Rsv2.

Grande parte da literatura cita a resistência vertical, que se mostra, de modo geral, menos estável que a horizontal. A constatação da quebra da resistência do cultivar IAC-Foscarin-31, em inoculações realizadas na Seção de Virologia Fitotécnica do IAC (Scagliusi et al., 1992), exemplifica tal possibilidade. Em razão disso, tem-se procurado introduzir resistência horizontal nos genótipos IAC de soja, com base na seleção em gerações sucessivas de sementes com baixo grau de "mancha-café".

Neste trabalho, são relatadas observações sobre ciclos de seleção em diversas linhagens para resistência ao grau de sementes manchadas, o desempenho desse germoplasma, em condições de campo, e o efeito da época de inoculação do vírus do mosaico comum sobre alguns desses genótipos em casa de vegetação.

\section{MATERIAL E MÉTODOS}

Toda a experimentação se desenvolveu no Centro Experimental de Campinas, pertencente ao IAC. As seleções de linhagens foram realizadas em campo, as avaliações de "mancha-café" em sementes, sob condições de laboratório, e as inoculações do vírus, em casa de vegetação.

\subsection{Avaliação de sementes com "mancha-café" em linhagens em 1987}

$\mathrm{Na}$ geração $\mathrm{F}_{4}$ do cruzamento entre IAC78-2318 e 'Santa Rosa', selecionaram-se 200 plantas em 1986, segundo o método genealógico modificado (SSD). Cada uma delas originou uma linhagem com o prefixo IAC87-, cuja semeadura se deu em 20/11/1987 em linha de $2 \mathrm{~m}$ de comprimento, espaçadas de $0,6 \mathrm{~m}$.

Fez-se a seleção, observando-se, principalmente, a altura das plantas e a resistência ao acamamento. As linhagens selecionadas, juntamente com os pais, foram colhidas e avaliadas quanto à intensidade de sementes manchadas, de acordo com uma escala de notas variando de 1 a 5 (Figura 1). 


\subsection{Avaliação da produção e da incidência de sementes com "mancha-café" em linhagens em 1988}

Para estudar a repetibilidade do manchamento de sementes dentro das linhagens IAC87-, instalou-se, em 8/12/1987, um experimento em campo, englobando o seguinte germoplasma: as quatro linhagens que receberam nota 1 , três linhagens com nota 2 , três com nota 3 , três com nota 4 e três com nota 5, e os parentais 'Santa Rosa' e IAC782318, perfazendo 18 tratamentos. O delineamento usado foi de blocos ao acaso, com seis repetições. Cada parcela foi constituída de uma linha com 2 $\mathrm{m}$ de comprimento, espaçada de $0,5 \mathrm{~m}$ da seguinte. A colheita se deu em $12 / 5 / 1988$, coletando-se os dados de produção e atribuindo-se notas às sementes, da forma anterior. Os dados de produção foram analisados e as médias, comparadas pelo teste de Tukey ao nível de $5 \%$.

\subsection{Efeito do VMCS sobre produção, número de sementes, "mancha-café", massa de cem sementes e ocorrência de haste verde em genótipos de soja infectados em três estádios fenológicos}

Utilizaram-se as seguintes linhagens com os respectivos graus de manchamento de sementes: IAC87-5934 (nota 1), IAC87-5908 (nota 2), IAC87-5896 (nota 3), IAC87-5977 (nota 4) e IAC87-5856 (nota 5), o cultivar Santa Rosa como controle suscetível, além de dois genótipos quase isogênicos ao controle, IAC-Santa Rosa PC (pubescência cinza) e IAC-Santa Rosa DF (com deficiência na utilização de $\mathrm{Fe}$ em solos alcalinos).

O delineamento foi um fatorial $(8 \times 4)$, com seis repetições. Cada parcela constou de um vaso (capacidade de $15 \mathrm{~kg}$ de terra) com três plantas.

Escolheu-se o isolado SMV-8, da coleção da Seção de Virologia Fitotécnica do IAC, pela sua capacidade de causar sintomas severos em diversos genótipos de soja. As preparações virais foram extraídas de folhas novas de plantas infectadas, em presença de tampão fosfato $0,02 \mathrm{M} \mathrm{pH} \mathrm{7,} \mathrm{ao} \mathrm{qual}$ se adicionou sulfito de sódio para alcançar também a concentração $0,02 \mathrm{M}$.
As inoculações foram realizadas em três épocas: aos 12, 21 e 32 dias após a semeadura (13/3/1992), respectivamente, nos estádios $V_{2}-V_{3}, V_{5}-V_{6}$ e $R_{1}$, segundo a escala de Fehr et al. (1971), ficando um dos tratamentos sem inoculação, constituindo a testemunha.

Após a maturação, as plantas foram colhidas, anotando-se: a massa e o número de sementes por vaso (parcela), as notas referentes à "mancha-café" (Figura 1); a presença do sintoma conhecido como haste-verde (não maturação đa planta), e a massa de cem sementes, obtida pela multiplicação por 100 do quociente massa/número de sementes por vaso.

As notas foram transformadas para a escala raiz quadrada de $(x+0,5)$ e, para as demais variáveis estudadas, os dados foram analisados sem transformações e as médias também comparadas pelo teste de Tukey a $5 \%$. Efetuou-se a correlação linear entre os caracteres estudados para relacionar os dados de "mancha-café" com os demais parâmetros. Com as sementes oriundas da primeira época de inoculação, determinou-se a taxa de transmissibilidade por semente, dada pelo quociente entre o número de plântulas com sintoma característico da virose sobre o total de plântulas germinadas, multiplicado por 100 .

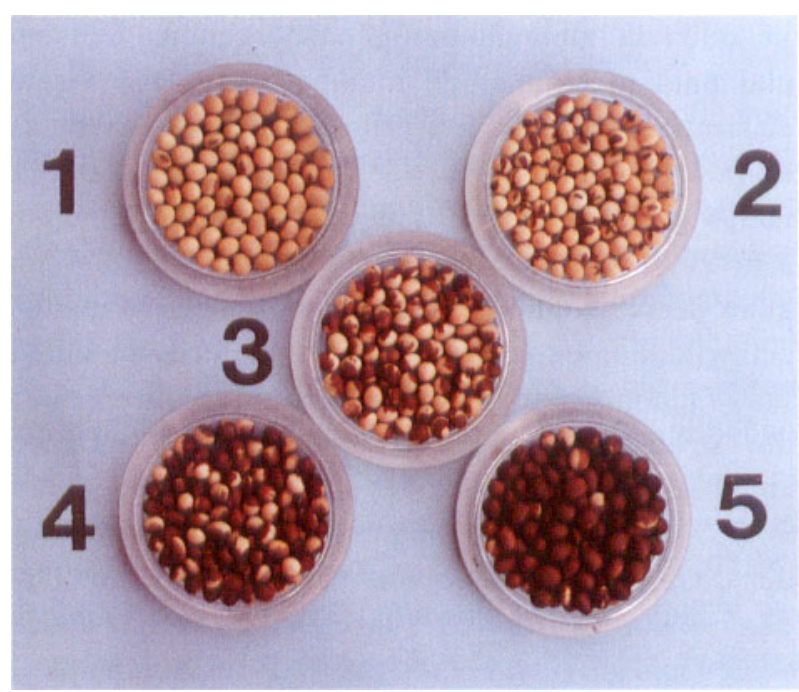

Figura 1. Escala de notas de manchamento de sementes de soja pelo vírus do mosaico comum (VMCS). (Nota 1: sementes sem manchas ... Nota 5: sementes com tegumento quase totalmente manchado). 


\section{RESULTADOS E DISCUSSÃO}

\subsection{Avaliação de sementes com "mancha-café" em linhagens em 1987}

Das 200 linhagens com prefixo IAC87-, selecionaram-se 131 , com bom porte e resistência ao acamamento. A avaliação desse germoplasma em relação ao manchamento das sementes apresentou os seguintes resultados: 4 linhagens com nota 1; 17 com nota $2 ; 58$ com nota $3 ; 35$ com nota 4 e 17 com nota 5. Os pais, 'Santa Rosa' e IAC78-2318 , obtiveram nota 3 e 4 respectivamente, e o cultivar IAC-11, considerado resistente, mostrou, nas mesmas condições experimentais, sementes sem sintomas (nota 1).

Essa distribuição de notas entre as 131 linhagens com predominância da classe intermediária (Figura 2) pode indicar que a herança do grau de manchamento da semente é de origem poligênica. Nesse cruzamento, portanto, não existiria relação gene a gene entre hospedeiro e patógeno, em contraposição aos dados de literatura.

Já se conhecia o comportamento de suscetibilidade dos pais em relação à "mancha-café" nas sementes. No caso do 'Santa Rosa', esse foi o fator mais importante na redução da área plantada no Estado de São Paulo, dificultando a obtenção de sementes dentro dos padrões estabelecidos pelas entidades certificadoras e fiscalizadoras de sementes, os quais toleram, no máximo, 5\% de sementes manchadas (CATI, 1986).

Em vista desse problema, verificado no 'Santa Rosa' e em outros cultivares e linhagens, o programa de melhoramento de soja do IAC incluiu, há anos, a seleção contra a suscetibilidade ao VMCS, nas etapas iniciais do melhoramento, com descarte de todo o material que apresentasse mancha nas sementes e sintomas característicos da moléstia na planta. Com a adoção dessa diretriz, os últimos cultivares de soja lançados pelo IAC têm mostrado baixo nível de sementes manchadas, inferior ao limite de 5\% (Razera et al., 1992). Conforme alertam Ford et al. (1989), a presença de manchas no tegumento não deve ser interpretada como diagnose para o VMCS porque o "bean pod mottle virus"
(BPMV) e o "peanut mottle virus" (PMV) também podem causar manchas na semente de cultivares resistentes ao VMCS; portanto, o tegumento manchado observado por Razera et al. (1992) em 'IACFoscarin-31', 'IAC-9' e 'IAC-11' pode ter sido causado por outras viroses.

\subsection{Avaliação da produção e da incidência de sementes com "mancha-café" em linhagens em 1988}

Os dados de produção e de "mancha-café" encontram-se no quadro 1. As linhagens apresentaram

Quadro 1. Notas $\left({ }^{1}\right)$ de "mancha-café" e produção de 17 linhagens e um cultivar de soja, em condições de campo, em Campinas, 1987-88

\begin{tabular}{cccc}
\hline \multirow{2}{*}{ Tratamento } & \multicolumn{2}{c}{$\left.\operatorname{Notas}^{2}\right)$} & Produção $\left({ }^{2}\right)$ \\
\cline { 2 - 3 } & 1987 & 1988 & 1987 \\
\hline
\end{tabular}

g

\begin{tabular}{llll} 
IAC87-5845 & 5 & $5,0 \mathrm{a}$ & $172 \mathrm{c}-\mathrm{f}$ \\
IAC87-5856 & 5 & $4,7 \mathrm{ab}$ & $115 \mathrm{~g}$ \\
IAC87-5882 & 5 & $4,6 \mathrm{ab}$ & $129 \mathrm{efg}$ \\
IAC87-5929 & 4 & $4,0 \mathrm{bc}$ & $164 \mathrm{c}-\mathrm{g}$ \\
IAC87-5770 & 4 & $3,8 \mathrm{~cd}$ & $211 \mathrm{bc}$ \\
IAC87-5977 & 4 & $3,4 \mathrm{cde}$ & $138 \mathrm{efg}$ \\
IAC87-5858 & 3 & $3,3 \mathrm{cde}$ & $203 \mathrm{bcd}$ \\
IAC78-2318 & 4 & $3,1 \mathrm{def}$ & $152 \mathrm{efg}$ \\
IAC87-5848 & 3 & $3,0 \mathrm{efg}$ & $203 \mathrm{bcd}$ \\
IAC87-5896 & 3 & $2,5 \mathrm{fgh}$ & $170 \mathrm{c}-\mathrm{f}$ \\
Santa Rosa & 3 & $2,4 \mathrm{gh}$ & $248 \mathrm{~b}$ \\
IAC87-5945 & 2 & $2,0 \mathrm{hi}$ & $174 \mathrm{cde}$ \\
IAC87-5908 & 2 & $2,0 \mathrm{hi}$ & $338 \mathrm{a}$ \\
IAC87-5956 & 2 & $1,8 \mathrm{ij}$ & $208 \mathrm{bc}$ \\
IAC87-5971 & 1 & $1,3 \mathrm{jk}$ & $157 \mathrm{~d}-\mathrm{g}$ \\
IAC87-5975 & 1 & $1,2 \mathrm{k}$ & $233 \mathrm{~b}$ \\
IAC87-5974 & 1 & $1,2 \mathrm{k}$ & $124 \mathrm{fg}$ \\
IAC87-5934 & 1 & $1,0 \mathrm{k}$ & $149 \mathrm{efg}$ \\
\hline & & & \\
\hline Média & & 2,8 & 183 \\
CV\% & & 8,9 & 23,6 \\
dms5\% & & & 50 \\
& & &
\end{tabular}

(1) Nota 1: sementes sem mancha; ... 5: sementes com tegumento quase totalmente manchado.

( ${ }^{2}$ Médias seguidas de letras distintas na coluna diferem entre si pelo teste de Tukey a $5 \%$. 


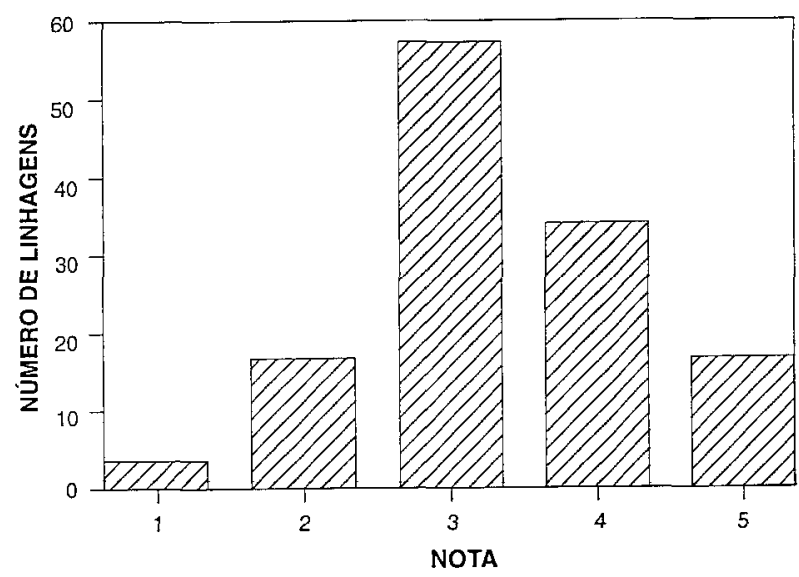

Figura 2. Frequiência de notas de manchamento de sementes pelo vírus do mosaico comum (VMCS) em 131 linhagens de soja descendentes de cruzamento entre IAC78-2318 e 'Santa Rosa', em condições de campo. Campinas, 1987.

(Nota 1: sementes sem manchas; ... Nota 5: sementes com tegumento quase totalmente manchado)

variação em relação ao grau de sementes manchadas, conforme se vê pelo gradiente de notas - 1 a 5 - com diferenças significativas. Também estão tabuladas as notas de sementes manchadas de 1987 , quando os dezoito genótipos em estudo faziam parte do elenco de 131 linhagens. Houve similaridade entre as notas atribuídas às linhagens, em 1987, e as médias obtidas no ensaio de 1988 , sendo o valor do coeficiente de correlação ( $r=0,96$ ) altamente significativo. Comparando-se as notas com a produtividade, verifica-se que, das quatro linhagens que receberam nota 1 nos dois anos, apenas IAC 87-5975 produziu acima de $200 \mathrm{~g} /$ parcela, tendo as três restantes produções menores. O coeficiente de correlação $(r=-0,27)$, nesse caso, indica que não há relação entre menor nota e maior produção, conforme aponta Buzzell (1983). Isso ocorreu, provavelmente, porque as linhagens não foram selecionadas para maior produtividade.

A repetibilidade verificada nos dois anos no comportamento das linhagens em relação ao nível de manchas nas sementes fortalece a diretriz do programa de melhoramento da Seção de Legumi- nosas, por meio da qual se eliminam plantas e/ou linhagens com incidência de sementes com "mancha-café".

3.3 Efeito do VMCS sobre produção, número de semente, "mancha-café", massa de cem sementes e ocorrência de haste-verde, em genótipos de soja inoculados em três estádios fenológicos

\section{Produção}

Os resultados de produção ( $\mathrm{g} / 3$ plantas) (Quadro 2) mostram diferenças significativas para o efeito varietal. O cultivar Santa Rosa teve a melhor produção média, $20 \mathrm{~g}$, diferindo significativamente de IAC87-5977, IAC87-5896, IAC87-5856 e IAC-Santa Rosa DF. Verifica-se, também, a importância da época de inoculação do vírus, sendo os estádios iniciais de desenvolvimento das plantas mais sensíveis às inoculações, com reflexos diretos na produção. Assim, a testemunha (sem inoculação) apresentou produção diferente das plantas infectadas nos diferentes estádios de desenvolvimento. A inoculação, cujas perdas provocadas foram as mais drásticas, realizou-se no cstádio vegetativo mais próximo à germinação $\left(\mathrm{V}_{2}-\mathrm{V}_{3}\right)$, acarretandó uma redução na produção da ordem de $45 \% \mathrm{em}$ relação à média dos tratamentos sem inoculação. A produção das plantas infectadas em $V_{2}-V_{3}$, todavia, não diferiu daquelas inoculadas no estádio $\mathrm{V}_{5}$ V6. Ambas apresentaram redução de $38 \%$ na produção em relação à testemunha. A inoculação no estádio $R_{1}$ (florescimento) acarretou queda de produção de $30 \%$. Pela análise da variância, não se detectou efeito da interação genótipo versus época de inoculação. Essa drástica redução na produção, pela infecção precoce com o vírus, já foi apontada por Ross (1983), Hill et al. (1987), ElAmretz et al. (1987) e Kwon \& Oh (1983).

\section{Número de sementes}

A linhagem IAC87-5934 produziu, em média, o maior número de sementes, diferindo dos demais tratamentos (Quadro 3). Novamente IAC-Santa Rosa DF apresentou as piores médias, não diferindo 
Quadro 2. Efeito do vírus do mosaico comum (VMCS) sobre a produção de linhagens e cultivares de soja, submetidos à inoculação em três estádios fenológicos, em casa de vegetação em Campinas, 1992

\section{Produção}

Genótipo

\begin{tabular}{lcc}
\multicolumn{3}{c}{ Épocas de inoculação } \\
\hline $\mathrm{V}_{2}-\mathrm{V}_{3}$ & $\mathrm{~V}_{5}-\mathrm{V}_{6}$ & $\mathrm{R}_{1}$ \\
$\mathrm{~g} / 3$ plantas
\end{tabular}

\begin{tabular}{llllll} 
'Santa Rosa' & 15,1 & 19,9 & 17,2 & 27,8 & $20,0 \mathrm{a}$ \\
IAC-Santa Rosa PC & 15,1 & 15,5 & 18,8 & 25,9 & $18,8 \mathrm{ab}$ \\
IAC87-5908 & 14,6 & 15,4 & 16,5 & 26,1 & $18,1 \mathrm{abc}$ \\
IAC87-5934 & 14,4 & 15,3 & 19,8 & 22,9 & $18,1 \mathrm{a}-\mathrm{d}$ \\
IAC87-5977 & 11,5 & 13,5 & 16,4 & 25,2 & $16,7 \mathrm{bcd}$ \\
IAC87-5896 & 12,8 & 13,4 & 16,9 & 19,5 & $15,7 \mathrm{bcd}$ \\
IAC87-5856 & 10,4 & 11,9 & 13,8 & 24,8 & $15,2 \mathrm{~cd}$ \\
IAC-Santa Rosa DF & 11,8 & 13,5 & 15,0 & 19,4 & $14,9 \mathrm{~d}$ \\
\hline Média & $13,2 \mathrm{C}$ & $14,8 \mathrm{BC}$ & $16,8 \mathrm{~B}$ & $23,9 \mathrm{~A}$ & 17,2 \\
CV(\%) & & & & & 32,8
\end{tabular}

(1) Médias seguidas de letras distintas (minúsculas na coluna e maiúsculas na linha) diferem entre si pelo teste de Tukcy a $5 \%$.

Quadro 3. Efeito do vírus do mosaico comum (VMCS) sobre o número de sementes produzidas por linhagens e cultivares submetidos à inoculação em três estádios fenológicos, em casa de vegetação em Campinas, 1992

Número de sementes

\begin{tabular}{|c|c|c|c|c|c|}
\hline \multirow[t]{2}{*}{ Genótipo } & \multicolumn{3}{|c|}{ Épocas de inoculação } & \multirow{2}{*}{ Sem inoculação } & \multirow{2}{*}{ Média $\left({ }^{1}\right)$} \\
\hline & $\mathrm{V}_{2}-\mathrm{V}_{3}$ & $\mathrm{~V}_{5}-\mathrm{V}_{6}$ & $\mathrm{R}_{1}$ & & \\
\hline IAC $87-5934$ & 145 & 164 & 192 & 155 & $164 a$ \\
\hline IAC-Santa Rosa PC & 97 & 133 & 157 & 147 & $134 b$ \\
\hline IAC $87-5977$ & 105 & 110 & 155 & 162 & $133 b$ \\
\hline 'Santa Rosa' & 85 & 134 & 145 & 154 & $130 \mathrm{~b}$ \\
\hline IAC $87-5908$ & 107 & 114 & 146 & 149 & $129 b$ \\
\hline IAC $87-5856$ & 105 & 104 & 142 & 161 & $128 b$ \\
\hline IAC $87-5896$ & 103 & 110 & 159 & 126 & $125 \mathrm{bc}$ \\
\hline IAC-Santa Rosa DF & 72 & 94 & 136 & 121 & $106 \mathrm{c}$ \\
\hline $\begin{array}{l}\text { Média } \\
\text { CV }(\%)\end{array}$ & $102 \mathrm{C}$ & $120 \mathrm{~B}$ & $154 \mathrm{~A}$ & $147 \mathrm{~A}$ & $\begin{array}{c}131 \\
29,9\end{array}$ \\
\hline
\end{tabular}

( ${ }^{1}$ ) Médias seguidas de letras distintas (minúsculas na coluna e maiúsculas na linha) diferem entre si pelo teste de Tukey a $5 \%$. 
apenas de IAC87-5896. Há que destacar o elevado índice de fecundação, refletido no maior número de sementes, independentemente do genótipo, quando a inoculação se deu no estádio $R_{1}$, não se observando diferenças em relação ao controle (sem inoculação). As inoculações realizadas nas fases vegetativas reduziram $18 \%$ o número de sementes por vaso no estádio $\mathrm{V}_{5}-\mathrm{V}_{6}$ e $31 \%$ em $\mathrm{V}_{2}-\mathrm{V}_{3}$. Tais reduções se mostraram significativas tanto em comparação com o controle e com o $R_{1}$ como entre si.

\section{"Mancha-café"}

Com relação ao efeito da época de inoculação sobre o grau de manchas nas sementes (Quadro 4), verifica-se o bom comportamento de IAC87-5934, com os menores índices de "mancha-café", confirmando o desempenho observado no campo em 1987 e 1988 (Quadro 1). Essa linhagem apresentou o maior número de sementes nas três épocas de inoculação (Quadro 3), além de boa produção na pre- sença do vírus (Quadro 2). Não houve diferença no manchamento de sementes em função da época de inoculação, entre $V_{2}-V_{3}$ e $V_{5}-V_{6}$; as notas de "mancha-café" referentes a essas duas épocas indicaram valores que correspondem a índices elevados de manchamento, diferindo de $\mathrm{R}_{1}$, embora tendo este também nota alta (média de 3,4). A ocorrência de manchamento em sementes de alguns controles pode estar associada à entrada de afídeos na casa de vegetação, que, mesmo não colonizando as plantas, tenham veiculado o vírus das plantas infectadas para as sadias.

\section{Massa de cem sementes}

Em relação a este parâmetro, houve uma redução de $17,6,23,5$ e $33,1 \%$, respectivamente, para os estádios de inoculação $\mathrm{V}_{2}-\mathrm{V}_{3}, \mathrm{~V}_{5}-\mathrm{V}_{6}$ e $\mathrm{R}_{1}$ em comparação com a testemunha. A interação entre cultivares e linhagens foi significativa, mostrando comportamento discrepante entre tratamentos. Para o cultivar Santa Rosa e IAC-Santa Rosa DF, a

Quadro 4. Efeito do vírus do mosaico comum (VMCS) na incidência de sementes com "mancha-café" $\left({ }^{1}\right)$ em linhagens e cultivares de soja submetidos à inoculação em três estádios fenológicos, em casa de vegetação em Campinas, 1992

\begin{tabular}{llllll}
\hline & \multicolumn{5}{c}{ Nota de "mancha-café" ${ }^{2}$ ) } \\
\cline { 2 - 4 } Genótipo & \multicolumn{3}{c}{ Épocas de inoculação } & Sem inoculação & Média \\
\cline { 2 - 4 } & $\mathrm{V}_{2}-\mathrm{V}_{3}$ & $\mathrm{~V}_{5}-\mathrm{V}_{6}$ & $\mathrm{R} !$ & & \\
\hline IAC87-5856 & $4,9 \mathrm{aA}$ & $5,0 \mathrm{aA}$ & $3,5 \mathrm{bB}$ & $2,1 \mathrm{aC}$ & $3,9 \mathrm{a}$ \\
IAC-Santa Rosa DF & $5,0 \mathrm{aA}$ & $4,9 \mathrm{aA}$ & $3,6 \mathrm{abB}$ & $1,0 \mathrm{bC}$ & $3,6 \mathrm{~b}$ \\
IAC87-5977 & $4,7 \mathrm{abA}$ & $3,9 \mathrm{cB}$ & $3,9 \mathrm{aB}$ & $1,8 \mathrm{aC}$ & $3,6 \mathrm{bc}$ \\
'Santa Rosa' & $4,7 \mathrm{abA}$ & $4,9 \mathrm{aA}$ & $3,4 \mathrm{bcB}$ & $1,1 \mathrm{bC}$ & $3,5 \mathrm{bcd}$ \\
IAC-Santa Rosa PC & $4,7 \mathrm{abA}$ & $4,9 \mathrm{aA}$ & $3,1 \mathrm{cdB}$ & $1,0 \mathrm{bC}$ & $3,4 \mathrm{~cd}$ \\
IAC87-5896 & $4,5 \mathrm{bA}$ & $4,5 \mathrm{bA}$ & $3,5 \mathrm{bB}$ & $1,0 \mathrm{bC}$ & $2,9 \mathrm{e}$ \\
IAC87-5908 & $3,9 \mathrm{cA}$ & $3,6 \mathrm{cAB}$ & $3,3 \mathrm{bcB}$ & $1,0 \mathrm{bC}$ & $2,1 \mathrm{f}$ \\
IAC87-5934 & $2,5 \mathrm{dAB}$ & $2,3 \mathrm{~dB}$ & $2,7 \mathrm{dA}$ & $1,0 \mathrm{bC}$ & 3,3 \\
\hline Média & $4,4 \mathrm{~A}$ & $4,2 \mathrm{~A}$ & $3,4 \mathrm{~B}$ & $1,2 \mathrm{C}$ & 9,6 \\
CV(\%) & & & & \\
\hline
\end{tabular}

(1) Nota 1: sementes sem mancha; ... 5: sementes com tegumento quase totalmente manchado. $\left({ }^{2}\right)$ Médias seguidas de letras distintas (minúsculas na coluna e maiúsculas na linha) diferem entre si pelo teste de Tukey a $5 \%$. 
inoculação no estádio $\mathrm{V}_{2}-\mathrm{V}_{3}$ reduziu de tal forma o número de sementes (Quadro 3) que condicionou um efeito de compensação, aumentando a massa de cem sementes, que atingiu valores próximos aos da testemunha (Quadro 5). O mesmo não ocorreu em relação às linhagens e ao IAC-Santa Rosa PC, que sofreram reduções significativas. Na segunda e na terceira época de inoculação, todos os tratamentos diferiram da testemunha.

\section{Haste-verde}

Observou-se a ocorrência de haste-verde em plantas sem inoculação. A despeito desse fato, na média de todos os tratamentos, a primeira e a terceira épocas de inoculação diferiram da sem inoculação (Quadro 6). 'Santa Rosa' e 'IAC-Santa Rosa DF' apresentaram, em geral, maiores notas e, coincidentemente, a maior redução no número de sementes, por vaso, pela inoculação. Mascarenhas et a1. (1988) explicam a senescência anormal, ou presença de haste-verde, por qualquer fator que implique menor índice de fecundação, diminuindo o número de vagens condicionando acúmulo de substâncias metabolizadas em órgãos não reprodutivos.

Os coeficientes de correlação simples (Quadro 7) entre as cinco variáveis analisadas, quando os genótipos foram submetidos ao efeito da inoculação com VMCS, mostraram que a produção está diretamente correlacionada com o número e a massa de cem sementes e negativamente relacionada com notas de "mancha-café" e de haste-verde. O número de sementes por vaso, por sua vez, correlacionou negativamente com as notas de sementes manchadas e de senescência anormal (haste-verde). As notas de "mancha-café" estavam diretamente correlacionadas com as de haste verde e inversamente relacionadas à massa de cem sementes. Essa correlação seria de maior magnitude caso não houvesse o efeito de compensação pelo menor índice de fecundação (Quadro 7).

Os dados referentes à transmissibilidade pela semente (Quadro 8) indicam que a linhagem IAC87-5934 foi a única que não apresentou plântulas com sintomas característicos da virose, apesar do

Quadro 5. Efeito do vírus do mosaico comum (VMCS) sobre a massa de cem sementes produzidas por linhagens e cultivares de soja submetidos à inoculação em três estádios fenológicos, em casa de vegetação em Campinas, 1992

\begin{tabular}{|c|c|c|c|c|c|}
\hline \multirow{3}{*}{ Genótipo } & \multicolumn{5}{|c|}{ Massa de cem sementes $\left({ }^{1}\right)$} \\
\hline & \multicolumn{3}{|c|}{ Épocas de inoculaçāo } & \multirow{2}{*}{ Sem inoculação } & \multirow{2}{*}{ Média } \\
\hline & $\mathrm{V}_{2}-\mathrm{V}_{3}$ & $\mathrm{~V}_{5}-\mathrm{V}_{6}$ & $\mathrm{R}_{1}$ & & \\
\hline 'Santa Rosa' & $17,8 \mathrm{aA}$ & $15,0 \mathrm{aB}$ & $11,8 \mathrm{abC}$ & $17,9 \mathrm{aA}$ & $15,6 \mathrm{a}$ \\
\hline IAC-Santa Rosa DF & $16,5 \mathrm{abA}$ & $14,6 \mathrm{aB}$ & $11,2 \mathrm{abC}$ & $16,2 \mathrm{bcdA}$ & $14,6 b$ \\
\hline IAC-Saanta Rosa PC & $15,6 \mathrm{bcB}$ & $11,7 \mathrm{cC}$ & $12,0 \mathrm{aC}$ & $17,4 \mathrm{abcA}$ & $14,2 \mathrm{~b}$ \\
\hline IAC $87-5908$ & $14,1 \mathrm{cdB}$ & $13,5 \mathrm{abB}$ & $11,4 \mathrm{abC}$ & $17,4 \mathrm{abA}$ & $14,1 b$ \\
\hline IAC $87-5896$ & $12,5 \mathrm{deB}$ & $12,0 \mathrm{bcBC}$ & $10,5 \mathrm{abcC}$ & $15,5 \mathrm{dA}$ & $12,6 \mathrm{c}$ \\
\hline IAC $87-5977$ & $11,0 \mathrm{efBC}$ & $12,3 \mathrm{bcB}$ & $10,3 \mathrm{bcC}$ & $15,4 \mathrm{dA}$ & $12,3 \mathrm{~cd}$ \\
\hline IAC $87-5856$ & $9,9 \mathrm{fBC}$ & $11,4 \mathrm{cB}$ & $9,8 \mathrm{cC}$ & $15,8 \mathrm{cdA}$ & $11,7 \mathrm{de}$ \\
\hline IAC $87-5934$ & $10,0 \mathrm{fB}$ & $9,4 \mathrm{~dB}$ & $10,3 \mathrm{bcB}$ & $14,7 \mathrm{dA}$ & $11,1 \mathrm{e}$ \\
\hline Média & $13,4 \mathrm{~B}$ & $12,5 \mathrm{C}$ & $10,9 \mathrm{D}$ & $16,3 \mathrm{~A}$ & 13,3 \\
\hline $\mathrm{CV}(\%)$ & & & & & 10,3 \\
\hline
\end{tabular}

( $\left.{ }^{1}\right)$ Médias seguidas de letras distintas (minúsculas na coluna e maiúsculas na linha) diferem entre si pelo teste de Tukey a $5 \%$. 
Quadro 6. Efeito do vírus do mosaico comum (VMCS) sobre a presença de haste-verde $\left({ }^{1}\right)$ em linhagens e cultivares de soja submetidos à inoculação em três estádios fenológicos, em casa de vegetação em Campinas, 1992

Nota de haste-verde $\left(^{2}\right)$

\begin{tabular}{|c|c|c|c|c|c|}
\hline \multirow[t]{2}{*}{ Genótipo } & \multicolumn{3}{|c|}{ Épocas de inoculação } & \multirow{2}{*}{ Sem inoculação } & \multirow{2}{*}{ Média } \\
\hline & $\mathrm{V}_{2}-\mathrm{V}_{3}$ & $\mathrm{~V}_{5}-\mathrm{V}_{6}$ & $\mathrm{R}_{1}$ & & \\
\hline 'Santa Rosa' & $3,2 \mathrm{abcA}$ & $2,8 \mathrm{aA}$ & $3,5 \mathrm{aA}$ & $2,7 \mathrm{aA}$ & $3,0 \mathrm{a}$ \\
\hline IAC-Santa Rosa DF & $3,5 \mathrm{abA}$ & $3,0 \mathrm{aAB}$ & $3,2 \mathrm{abAB}$ & $2,3 \mathrm{abB}$ & $3,0 \mathrm{a}$ \\
\hline IAC-Santa Rosa PC & $3,7 \mathrm{aA}$ & $2,7 \mathrm{aA}$ & $2,8 \mathrm{abA}$ & $2,7 \mathrm{aA}$ & $3,0 \mathrm{ab}$ \\
\hline IAC $87-5896$ & $2,5 \mathrm{bcAB}$ & $2,0 \mathrm{aB}$ & $3,0 \mathrm{abAB}$ & $3,2 \mathrm{aA}$ & $2,7 \mathrm{ab}$ \\
\hline IAC $87-5856$ & $2,3 \mathrm{cA}$ & $2,7 \mathrm{aA}$ & $2,5 \mathrm{abcA}$ & $2,2 \mathrm{abA}$ & $2,4 b c$ \\
\hline IAC87-5977 & $2,8 \mathrm{abcA}$ & $2,3 \mathrm{aA}$ & $2,2 \mathrm{bcA}$ & $1,0 \mathrm{cB}$ & $2,1 \mathrm{c}$ \\
\hline IAC $87-5934$ & $1,2 \mathrm{~dB}$ & $2,0 \mathrm{aAB}$ & $2,5 \mathrm{abcA}$ & 2,3abA & $2,0 \mathrm{c}$ \\
\hline IAC $87-5908$ & $2,3 \mathrm{cA}$ & $2,3 \mathrm{aA}$ & $1,5 \mathrm{cA}$ & $1,3 \mathrm{bcA}$ & $1,9 \mathrm{c}$ \\
\hline Média & $2,7 \mathrm{~A}$ & $2,5 \mathrm{AB}$ & $2,6 \mathrm{~A}$ & $2,2 \mathrm{~B}$ & 2,5 \\
\hline $\mathrm{CV} \%$ & & & & & 39,6 \\
\hline
\end{tabular}

(1) Nota 1: maturação normal; ... 5: plantas verdes, com retenção foliar e vagens secas.

${ }^{2}$ ) Médias seguidas de letras distintas (minúsculas na coluna e maiúsculas na linha) diferem entre si pelo teste de Tukey a $5 \%$.

Quadro 7. Coeficientes de correlação simples (r) entre as variáveis nota de "mancha-café" (nota VMCS), produção, número de sementes, massa de cem sementes e nota de haste-verde (nota HV), obtidos de oito genótipos de soja submetidos ao efeito da inoculação do vírus do mosaico comum da soja (VMCS) cm três estádios fenológicos em Campinas, 1992

\section{Valores de $r$}

Variáveis

$\begin{array}{cccc}\text { Número } & \text { Nota } & \text { Nota } & \text { Massa } \\ \text { sementes } & \text { VMCS } & \text { HV } & \text { de cem } \\ \text { sementes }\end{array}$

$\begin{array}{lcccc}\text { Produção } & 0,81^{* *} & -0,53^{* *} & -0,24^{* *} & 0,4^{* *} \\ \text { Número sementes } & - & -0,36^{* *} & -0,31^{* * *} & -0,13 \mathrm{~ns} \\ \text { Nota VMCS } & - & - & 0,21^{* *} & -0,33^{* *} \\ \text { Nota HV } & - & - & - & 0,12 \mathrm{~ns}\end{array}$

ns - não significativo; ${ }^{*} \mathrm{p}<0,05 \mathrm{e}{ }^{* *} \mathrm{p}>0,01$. pequeno número de plantas observadas. Caso haja confirmação dessa menor transmissibilidade, a alternativa de seleção contra manchamento de semente deve diminuir a probabilidade de introdução do mosaico em novas áreas de cultivo de soja.

Como há evidências da relação gene a gene para a reação de hipersensibilidade entre patógeno-hospedeiro, para o caso do mosaico comum da soja (VMCS), existe um perigo potencial em relação à vulnerabilidade genética, pois quase todos os cultivares resistentes têm como um dos ancestrais o cultivar Ogden, que apresenta o alelo $r v^{t}$. Esse genótipo mostra reação necrótica quando submetido a determinadas estirpes do vírus. Tal risco fica mais evidente diante do relato de Kwon \& Oh (1980) sobre o aparecimento de uma estirpe na Coréia, com reação necrótica no cultivar Kwanggyo, que antes se mostrava resistente às estirpes prevalecentes. Assim, em contraposição ao uso de uma única fonte de resistência, Buss et al. (1989) indicam as alternativas: piramidização genética, multilíneas, "blends" e resistência à transmissão via semente. 
Quadro 8. Porcentagem de transmissão do VMCS por semente de linhagens e cultivares de soja (primeira época de inoculação), Campinas, 1992

Plântulas

observadas
Plântulas com sintomas de VMC
Plântulas infectadas

\begin{tabular}{lrrr}
\hline & & & $\%$ \\
\cline { 2 - 3 } IAC87-5934 & 230 & 0 & 0,0 \\
IAC87-5856 & 249 & 4 & 1,6 \\
IAC-Santa Rosa DF & 191 & 4 & 2,1 \\
'Santa Rosa' & 228 & 7 & 3,1 \\
IAC87-5896 & 241 & 8 & 3,3 \\
IAC-Santa Rosa PC & 217 & 9 & 4,2 \\
IAC87-5977 & 227 & 10 & 4,4 \\
IAC87-5908 & 212 & 18 & 8,5 \\
\hline
\end{tabular}

O programa de melhoramento da Seção de Leguminosas já vem utilizando a estratégia de lançar cultivares resistentes e cultivares suscetíveis com baixos índices de "mancha-café", os quais possuem, possivelmente, menor transmissibilidade pelas sementes. Dessa forma, evita-se a pressão de seleção para o surgimento de estirpes mais patogênicas, que poderiam quebrar a resistência conferida pelo alelo rvt.

\section{CONCLUSÕES}

1. Foi possível a discriminação de genótipos com diferentes graus de susceptibilidade ao mosaico comum em condições de campo em Campinas (SP).

2. As inoculações realizadas em casa de vegetação condicionaram infecçōes muito severas, impedindo a obtenção do mesmo gradiente de notas verificado para os genótipos avaliados em campo.

3. A linhagem IAC87-5934 apresentou a menor nota de "mancha-café" e não mostrou transmissão do vírus por semente.

\section{REFERÊNCIAS BIBLIOGRÁFICAS}

BUSS, G.R.; CHEN, P.; TOLIN, S.A. \& ROANE, C.W. Breeding soybeans for resistance to soybean mosaic virus. In: WORLD SOYBEAN RESEARCH CONFERENCE, 4., Buenos Aires, 1989. Actas-Proceedings. Buenos Aires, Pascale, A.J., ed., 1989. p.1182-1187.
BUZZELL, R.I. Tolerance/resistance to soybean mosaic virus. Soybean Genetics Newsletter, Ames, 10:9-10, 1983.

BUZZELL, R.I. \& TU, J.C. Inheritance of soybean resistance to soybean mosaic virus. Joumal of $\mathrm{He}$ redity, New York, 75:82, 1984.

COORDENADORIA DE ASSISTÊNCIA TÉCNICA INTEGRAL (CATI). Padrões de sementes 1986. Campinas, CATI, 1986. 42p.

CHO, E.K. \& GOODMAN, R.M. Strains of soybean mosaic virus: classification based on virulence in resistant soybean cultivars. Phytopatology, St. Paul, 69:467-470, 1979.

CHO, E.K. \& GOODMAN, R.M. Evaluation of resistance in soybeans to soybean mosaic virus strains. Crop Science, Madison, 22:1133-1136, 1982.

COSTA, A.S. Investigação sobre moléstias da soja no Estado de São Paulo. Summa Phytopathologica, Jaguariúna, 3(1):3-30, 1977.

COSTA, A.S.; MIYASAKA, S.; KIIHL, R.A.S. \& DEMATTÊ, J.D. Moléstias de vírus da soja em São Paulo. In: SIMPÓSIO BRASILEIRO DE SOJA, 1., Campinas, 1970. Resumos. Sociedade Brasileira de Fitopatologia, 1970. p.48-50.

COSTA LIMA NETO, V. da \& COSTA, A.S. Transmissão experimental do vírus do mosaico comum da soja com afídeos que ocorrem em trigo. In: CONGRESSO DA SOCIEDADE BRASILEIRA DE FITOPATOLOGIA, 8., Mossoró, 1975. Resumos, Mossoró, Sociedade Brasileira de Fitopatologia, 1975. p.143.

COSTA LIMA NETO, V. da \& COSTA A.S. Transmissão comparativa do vírus do mosaico comum da soja por sementes com mancha-café e não manchadas. In: CONGRESSO DA SOCIEDADE BRASILEIRA DE FITOPATOlOGIA, 9., Campinas, 1976. Resumos. 
Campinas, Sociedade Brasileira de Fitopatologia, 1976. p.35.

EL-AMRETZ, A.A.; EL-SAID, H.M. \& SALEM, D.E. Evaluation of response of different soybean cultivars to soybean mosaic virus infection. Agricultural Research Review, Cairo, 63:145-153, 1987.

FEHR, W.R.; CAVINESS, C.E.; BURMOOD, D.T. \& PENNINGTON, J.S. Stage of development descriptions for soybeans, Glycine max (L.) Merrill. Crop Science, Madison, 11:929-931, 1971.

FORD, R.E.; JILKA, J.M. \& TOLIN, S.A. Viral diseases in soybean. In: WORLD SOYBEAN RESEARCH CONFERENCE, 4., Buenos Aires, 1989. Actas-Proceedings. Buenos Aires, Pascale, A.J., ed., 1989. p.1312-1355.

HILL, J.H.; BAIELY, T.B.; BENNER, H.I.; TACHIBANA, H. \& DURAND, D.P. Soybean mosaic virus: effects of primary disease incidence on yield and seed quality. Plant Disease, St. Paul, 71:237-239, 1987.

JUNYI, G.L.; HU, Y.Z.; ZHANG, Y.D.; XIANG, Y.D. \& MA, R.H. Inheritance of resistance of soybeans to four local strains of soybean mosaic virus. In: WORLD SOYBEAN RESEARCH CONFERENCE, 4., Buenos Aires, 1989. Actas-Proceedings. Buenos Aires, Pascale, A.J., ed., 1989. p. 1182-1187.

KIIHL, R.A.S. \& HARTWIG E.E. Inheritance of reaction to soybean mosaic virus in soybeans. Crop Science, Madison, 19:372-375, 1979.

KWON, S.H. \& OH, J.H. Resistance to a necrotic strain of soybean mosaic virus in soybean. Crop Science, Madison, 20:403-404, 1980.

KWON, S.H. \& OH, J.H. Induced mutation for soybean mosaic virus disease resistance on soybean. In:
Induced mutations for disease resistance in crop plants. II. Vienna, International Atomic Energy Agency, 1983. p.183-191.

LIM, S.M. Resistance to soybean mosaic virus in soybeans. Phytopathology, St. Paul, 75:199-201, 1985.

MASCARENHAS, H.A.A.; MIRANDA, M.A.C. de; NOGUEIRA, S.S.S. \& BULISANI, E. Senescência anormal decorrente de distúrbios fisiológicos. $O$ Agronômico, Campinas, 40(2):130-138, 1988.

RAZERA, L.F.; ROSSETTO, C.J.; MEDINA, P.F.; TISSELLI FILHO, O,; IGUE, T. \& BARRADAS, M.M. Melhoramento da soja para resistência à multiadversidade ambiente. III. Levantamento de "mancha-café" em sementes básicas no período 1981-1988. Revista de Agricultura, Piracicaba, 67(1):97-104, 1992.

ROSS, J.P. Pathogenic variation among isolates of soybean mosaic virus. Phytopathology, St. Paul, 59:829$832,1969$.

ROSS, J.P. Effect of soybean mosaic on component yields from blends of mosaic resistant and susceptible soybeans. Crop Science, Madison, 23:343-346, 1983.

SCAGLIUSI, S.M.M.; COSTA, A.S. \& VEGA, J. Isolation of a strain of soybean mosaic virus that invades the resistant cultivar Foscarin 31 and induces mosaic. In: ENCONTRO NACIONAL DE VIROLOGIA, 6. São Lourenço, 1992. Programas e Resumos. Sociedade Brasileira de Virologia, 1992. p.175.

SINCLAIR, J.B. Compendium of soybean diseases. St. Paul, The American Phytopathological Society, 1982. 104p.

YORINORI, J.T. Doenças da soja no Brasil. In: A soja no Brasil Central. Campinas, Fundação Cargill, 1982. p.301-364. 